\title{
The Impact of Oncology Rotation on Medical Students' Perception of Cancer
}

\author{
Cristina Lungulescu ${ }^{1}$, Mihaela Dănciulescu ${ }^{2}$, Ștefan Răileanu ${ }^{2}$ \\ ${ }^{1}$ Department of Oncology, University of Medicine and Pharmacy of Craiova, Romania \\ 2 Department of Oncology, Filantropia Clinical Hospital, Craiova, Romania
}

Corresponding author: Cristina Lungulescu; e-mail: cristinalungulescu@yahoo.com

\section{Abstract}

Background: Cancer is a major health concern globally, with accelerated advancements in terms of understanding its physiopathology and treatment protocols. These rapid advancements make the determination of the ideal method of educating students in Medical Oncology increasingly difficult. The purpose of this research paper is to evaluate how students from the University of Medicine and Pharmacy of Craiova, Romania perceive certain topics related to cancer and the specialty of Medical Oncology, in order to improve their education in this field.

Material \& Methods: We compared questionnaires consisting of 28 scaled-response questions and one free-response question filled in by 40 students at the beginning and end of their oncology clinical rotation. The questions were assigned numerical values so that statistical analysis could be performed.

Results: After their clinical oncology rotation, students in the Faculty of Medicine had more confidence in diagnosing cancer ( $p=0.012)$, and had a better understanding of the implication of the side effects of treatment in patients who can no longer be cured $(p=0.04)$. Students in the Faculty of Nursing were better able to understand the risks and benefits of treatment after their clinical oncology rotation $(p=0.007)$ and had increased confidence in recognizing cancer symptoms $(\mathrm{p}=0.001)$.

Conclusion: The results of our study show that after clinical placement, students experienced an increase in empathy for cancer patients; correspondingly, there was an increased likelihood that students would consider oncology as a specialty in the future. Students began to recognize cancer as a chronic condition and were better able to consider the psychosocial issues after their clinical placement.

Keywords: oncology, medical students, survey, undergraduate education, career 


\section{Introduction}

Cancer is a major health concern globally, with more than $50 \%$ of people born after 1960 developing a form of cancer in their lifetime (1).

Because modern treatments are able to prolong survival in many patients, cancer requires medical care comparable to chronic diseases. The disease is therefore managed by various health care professionals, not only those working in oncology (2). Students who will pursue careers as family practitioners, general physicians, radiologists, pathologists and surgeons will participate, to a various extent, in procedures complementary to the field of oncology, such as prevention, screening, diagnosis, and follow-up (3).

A survey conducted in the UK revealed that only $10 \%$ of newly qualified doctors felt confident managing oncological emergencies, and only $15 \%$ felt they possessed sufficient knowledge regarding chemotherapy and radiotherapy (4). Another study involving interns in Australia and New Zealand showed that two-thirds of the surveyed participants were unaware of the prognosis of certain malignancies, and that one-third felt they were unable to identify a melanoma reliably (5).

As our understanding of oncological diseases evolves and treatment protocols change, determining the ideal method of educating students in Medical Oncology becomes increasingly difficult, requiring longer periods of study for students to effectively incorporate all knowledge. By consulting with students, valuable improvements in the educational process can be made.

The discipline of 'Oncology' is taught in the Faculty of Medicine during the fifth year of study for an entire semester, which is 14 weeks long. The theoretical concepts are taught during a weekly two-hour course. This is followed by clinical rotations in the oncology departments of university hospitals. The clinical rotation is scheduled for 2 hours a week, and allows students to parti- cipate in the diagnosis and treatment of patients with malignant diseases, under the strict guidance of medical oncologists. The discipline 'Nursing Oncology' is intended for students of the Faculty of Nursing during the fourth year of study. Similarly, the subject is taught over 14 weeks, with students attending classes and participating in weekly clinical rotations.

The purpose of this research was to evaluate how students of the Faculty of Medicine and the Faculty of Nursing at the University of Medicine and Pharmacy of Craiova, Romania, perceived the treatment experience of cancer patient prior to and following their mandatory rotation in Oncology.

\section{Material \& Methods}

\section{Participants}

This study included two groups of students: one group composed of 5th year medical students enrolled in the Faculty of Medicine, and a second group composed of 4th year students enrolled in the of the Faculty of Nursing, who performed their Oncology training at the University of Medicine and Pharmacy Craiova, with a clinical rotation in the Department of Oncology at 'Filantropia' Clinical Hospital in Craiova, Romania.

\section{Study design}

At the beginning and the end of their Oncology training, students were invited to fill out a questionnaire that was initially designed, piloted and conducted on third-year medical students attending a two-week rotation in oncology and palliative care in Freeman Hospital, Newcastle upon Tyne, UK (6). The questionnaire consisted of 28 scaledresponse questions. Twenty-seven questions were designed using a six-point Likert scale ranging from 'strongly agree' to 'strongly disagree', while the $28^{\text {th }}$ question "Would you consider a career in oncology?" 
had the following answers: "Yes", "No", or "Maybe" (Table 1). The questionnaire also included one question inviting a free text response: "Why would you/would you not consider a career in oncology?".

We distributed identical questionnaires to students from both faculties on the first and last day of their clinical oncology rotation, and we anonymized them by assigning a study number to each of the students who completed the questionnaire. Student participation was voluntary.

Table 1. Statements used in the questionnaire (6).

\begin{tabular}{|c|c|}
\hline $\begin{array}{l}\text { Statement } \\
\text { number }\end{array}$ & Statement \\
\hline 1 & I believe cancer should be approached as a chronic condition. \\
\hline 2 & $\begin{array}{l}\text { I feel death and dying are too strongly emphasized in patients with cancer, compared to } \\
\text { other illnesses. }\end{array}$ \\
\hline 3 & In my opinion, cancer is likely to leave the patient with significant long-term morbidity. \\
\hline 4 & I always associate cancer with a shortened duration of life. \\
\hline 5 & I tend to feel optimistic about the outcome of current cancer treatments. \\
\hline 6 & I feel oncology is a depressing specialty. \\
\hline 7 & $\begin{array}{l}\text { I believe a physician should disregard side effects if the treatment will prolong life in a } \\
\text { patient who can no longer be cured. }\end{array}$ \\
\hline 8 & $\begin{array}{l}\text { I believe when exploring what a diagnosis may mean, the physician should lead the } \\
\text { discussion not the patient. }\end{array}$ \\
\hline 9 & $\begin{array}{l}\text { I believe physicians should place more importance on cancer management than a person's } \\
\text { social and psychological factors. }\end{array}$ \\
\hline 10 & I believe patients have adequate opportunity to participate in choosing their treatment. \\
\hline 11 & I believe clinicians are attentive to the symptoms and problems of cancer patients. \\
\hline 12 & I believe cancer patients should be well informed about their prognosis and diagnosis. \\
\hline 13 & $\begin{array}{l}\text { I believe psychosocial aspects are adequately considered and addressed in patients with } \\
\text { cancer. }\end{array}$ \\
\hline 14 & I believe that information about diagnosis and prognosis can be detrimental to the patient. \\
\hline 15 & I feel uncomfortable using the word "cancer" with patients. \\
\hline 16 & I believe patients who can no longer be cured should be encouraged to enter clinical trials. \\
\hline 17 & I believe clinicians deliberately avoid using the word "cancer" when dealing with patients. \\
\hline 18 & $\begin{array}{l}\text { I believe patients receive unacceptable toxicity in relation to benefit they gain when } \\
\text { receiving systemic chemotherapy. }\end{array}$ \\
\hline 19 & I believe all anti-cancer treatment should improve quality of life. \\
\hline 20 & I believe discussion and implementation of end-of-life care has a positive impact. \\
\hline 21 & I believe multidisciplinary team involvement is advantageous to individual patient care. \\
\hline 22 & I believe all anti-cancer treatment should prolong life. \\
\hline 23 & I feel confident in my ability to break bad news to patients. \\
\hline 24 & I am aware of complications of management of cancer. \\
\hline 25 & I feel confident in recognizing red flag symptoms. \\
\hline 26 & In my opinion palliative care and cancer should be taught separately in the curriculum. \\
\hline 27 & I feel confident in making a diagnosis of cancer. \\
\hline 28 & Would you consider a career in oncology? \\
\hline
\end{tabular}




\section{Data Analysis}

The questionnaires were paired using candidate numbers. Numerical values from 1 to 6 were assigned to the first 27 questions, for 'strongly disagree' to 'strongly agree', respectively. The $28^{\text {th }}$ question was assigned numerical values from 1 to 3 . We performed data analysis using descriptive statistics and analysis of variance. The responses to the qualitative question were re- viewed both individually and together, to identify recurrent themes.

\section{Results}

In total, 40 students participated in the study: 15 students from the Faculty of Medicine and 25 from the Faculty of Nursing.

The mean of the responses to the first 27 questions, before and after the clinical placement, are displayed in Figures 1 and 2.

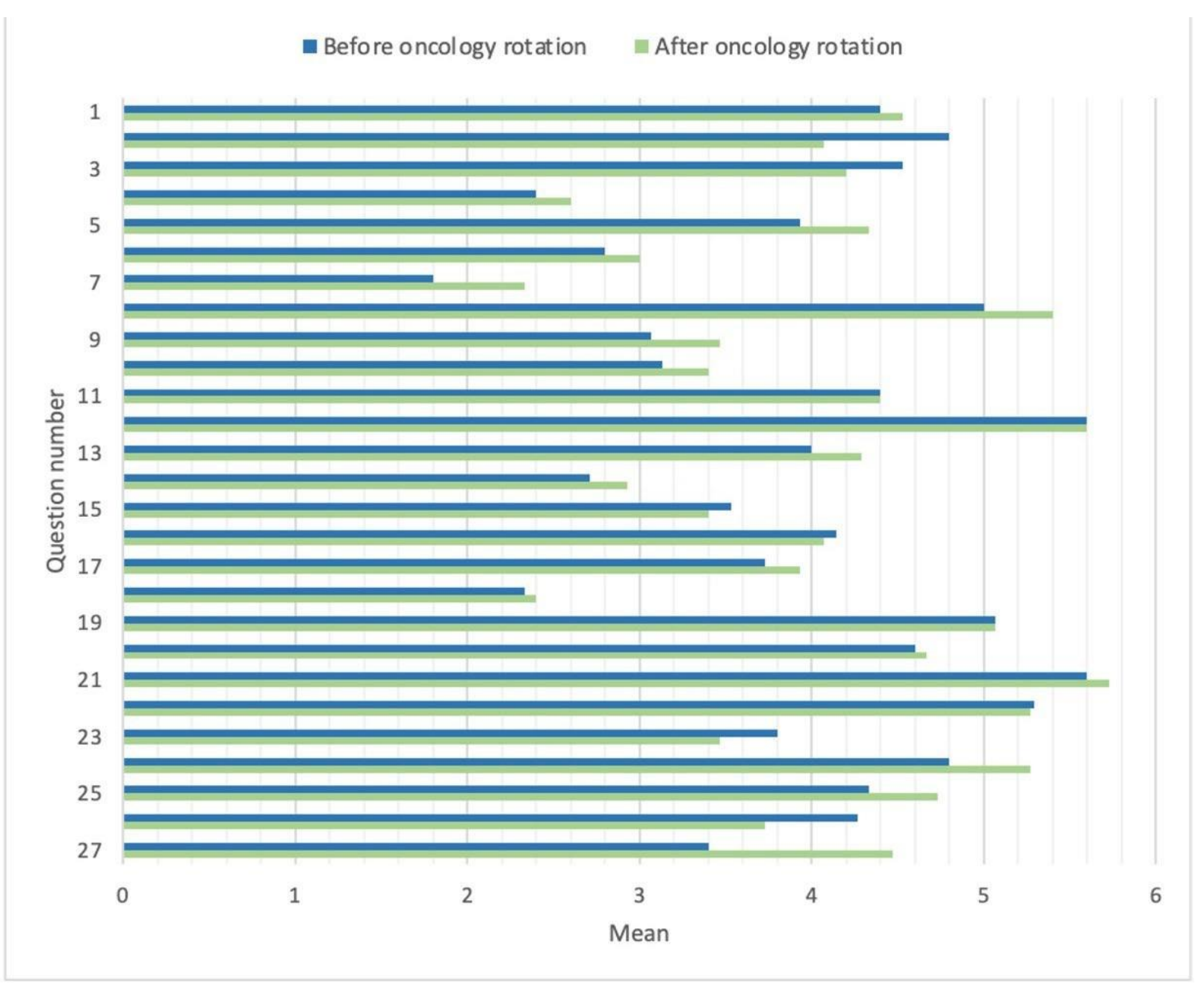

Fig. 1: Responses to the first questions before and after clinical placement - Faculty of Medicine

\section{Faculty of Medicine}

15 participants completed the survey: $60 \%$ were female $(n=9)$ and $40 \%$ were male $(n=6)$. The most striking differences between students were in student confidence in diagnosing cancer $(p=0.023$, question 27) and in the manner they perceived side effects of treatment in patients with incurable cancer $(p=0.04$, question 7). After the oncology rotation, students strongly agreed (mean $=4.47$ ) with the statement, "I feel confident in making a diagnosis of cancer" when compared to their 
responses prior to the rotation (mean $=3.5$ ). Before the rotation, medical students were less likely to believe a physician should disregard side effects in patients who cannot be cured (mean=1.8), than after the rotation $($ mean $=2.33)$.

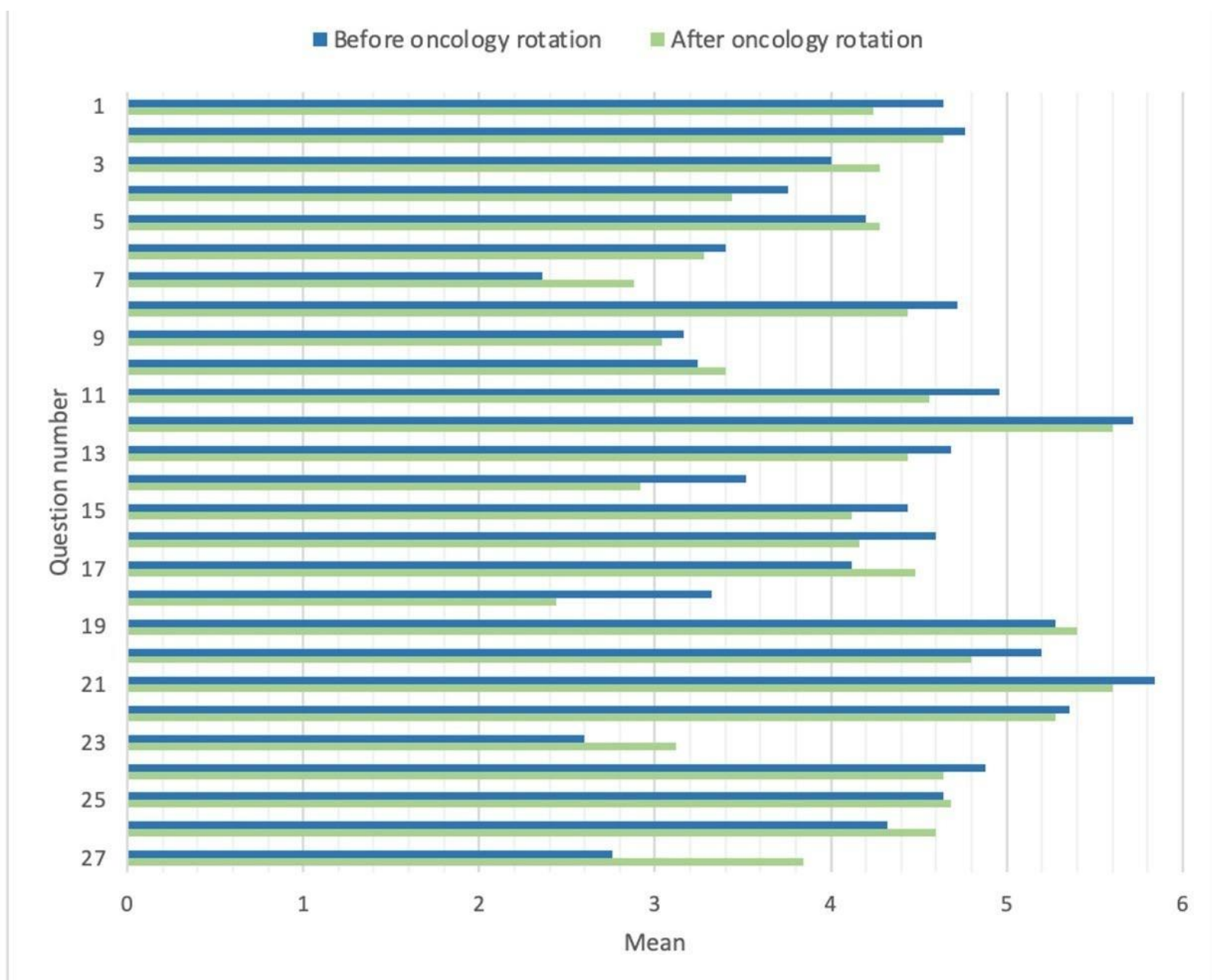

Fig. 2: Responses to the first 27 questions before and after clinical placement - Faculty of Nursing

The strongest areas of agreement among responders were that patients should be wellinformed about their prognosis and diagnosis, that the involvement of the multidisciplinary team is beneficial for individual patient care, and that palliative care can have a positive impact on the patient and the family. Similarly, both during and after the rotation, students did not agree on whether they always associated cancer with a short lifespan.

Prior to oncology training, five students at the Faculty of Medicine stated that they would consider a career in oncology, two stated that they would not, and 8 were undecided. After the oncology rotation, eight students said they would consider a career in oncology, one said they would not, and six remained undecided (Figure 3).

Reasons students cited for interest in the specialty of Medical Oncology included the opportunity to work in a multidisciplinary team, and the ability to provide treatments and perform research that can have a major impact on patients' lives. The most common reasons for the lack of interest in the specialty were the difficulty in managing the multitude of symptoms, and the challenge of the psychosocial and spiritual complexity of cancer patients. 


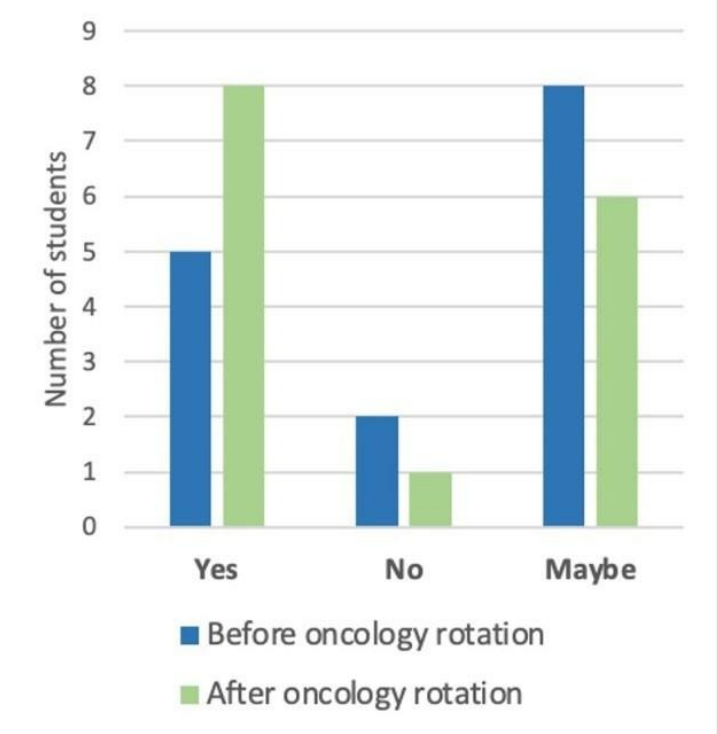

Fig. 3: Responses to question 28 - Faculty of Medicine

\section{Faculty of Nursing}

Twenty-five participants completed the survey: $88 \%$ were female $(n=22)$ and $12 \%$ were male $(n=3)$.

The most significant changes were in students' improved understanding of the benefits of chemotherapy post-clinical rotation ( $p=0.007$, question 18$)$ found in question 18 (mean before $=2.44$, mean after $=3.32 ; p=0.007$ ) Furthermore, students reported greater confidence in their ability to recognize cancer (question 27, $\mathrm{p}=0.001$ ) after the clinical rotation (mean=3.84) when compared to before (mean=2.76).

Like the students in the Faculty of Medicine, students in the Faculty of Nursing strongly believed that cancer patients should be informed about their prognosis and diagnosis, that cancer treatment should improve the patients' quality of life, and that the involvement of a multidisciplinary team is advantageous for individual patient care.

Prior to oncology training, one student stated that they would consider a career in oncology, nine students were opposed, and fifteen were undecided. After the training, eight students said they would consider a career in oncology, five said they would not, and twelve remained undecided (Figure 4).

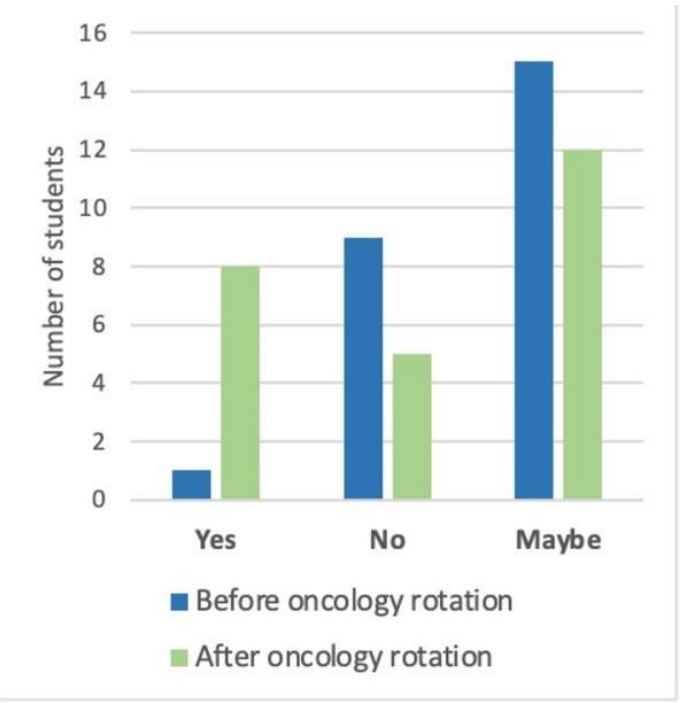

Fig. 4: Responses to question 28 - Faculty of Nursing

The main reasons to select oncology as a career in nursing were the ability to developing-term relationships with patients and their families, and the gratitude expressed by patients. The most common justification for lack of interest in the specialty was that oncology care can be "too depressing" or "an emotional burden".

\section{Discussion}

The increase in the aging population in developed countries contributes to the increase in the number of people that will be diagnosed and treated for cancer in the coming decades (7).

Our results show an increase in medical and nursing students' empathy for cancer patients following a clinical rotation in oncology and that specific training in oncology influences students' desires to pursue a career in oncology. Likewise, a study conducted at another institution analyzed the impact of a preclinical oncology course on medical school students and found that clinical training increased empathy towards cancer patients as well as the likelihood of stu- 
dents considering oncology as a profession (8). Furthermore, research suggests that students who receive more information about cancer treatment are more likely to have a positive attitude towards treating cancer patients (9). Similarly, we found that, after completing the clinical rotation, students felt more comfortable talking to cancer patients about both physical and psychosocial problems, including death. Students from both faculties gained confidence in recognizing cancer signs and symptoms, as indicated by the significantly different responses to question 27 (Faculty of Medicine, $p=0,012$; Faculty of Nursing, $p=0,001$ ) provided prior to and after clinical placement.

The results of our study show that all students strongly believe that patients should be informed about the diagnosis and prognosis of their disease. An international study has shown that most adults - healthy people, as well as cancer patients from different countries - have expressed a desire to be fully informed about the details of their health condition (10). Prior to 1960, most American physicians did not disclose the truth about their diagnosis to cancer patients (11). In the last two decades, most physicians in the United States and Northern Europe report that they usually fully inform cancer patients about their illness (12). Paradoxically, only a few doctors in these countries tell patients the full truth about the prognosis of their disease. There is also little data on whether physicians respect the wishes of educated patients to be fully informed.

A study contrasted medical and law students' perspectives about informing a cancer patient (who wishes, or alternatively, who does not wish to be told the truth) about diagnosis and prognosis (13). All students equally agreed to fully inform the patient about his diagnosis. However, a smaller percentage of medical students compared to law students agreed to share prognostic information if the patient wanted it $(p=$ 0.0003 ). Notably, more law students than medical students supported disclosing the patient's diagnosis $(35 \%$ vs. $11 \% ; p=$ $0.0004)$ and prognosis $(26 \%$ vs. $7 \% ; p=$ 0.0001 ) despite the patient's explicit request not to be informed. Disparities in attitudes toward information-giving (between law and medicine students) were a consequence of divergent assessments of whether the information will serve or hurt the patient. Medical students stated that their decisions regarding informing patients were impacted by the belief that physicians should respect the autonomy of their patients. However, law students stated deontological grounds more frequently than medical students, which allude to legal obligations, the avoidance of harm, and veracity. Those findings imply that more future physicians than future lawyers make a distinction between revealing the diagnosis and fully disclosing a dismal prognosis.

It is commonly expected that students will be able to work effectively in a team, withstand the rigors of a medical unit, understand the suffering caused by illness, and increase society's confidence in the healthcare system through their behavior. The results of our questionnaires show that after their clinical oncology rotation, students began to understand not only the chronic nature of cancer, but also the resulting psychosocial issues and the adverse effects of treatment. The strongest areas of agreement were that patients should be adequately apprised of their prognosis and diagnosis, that decision-making and subsequent treatment should involve a multidisciplinary team, and that palliative care can benefit the patient and family. Furthermore, the results of our study demonstrate that after clinical placement, there is an increased likelihood that students will pursue a career in oncology.

\section{Conclusions}

Our research shows that a clinical oncology rotation is correlated with a shift in students' knowledge and attitude towards oncology. 
Statements: None.

Previous publication: I declare that this paper was not published nor was submitted to be reviewed for publication in another journal.

Conflict of interest: I declare having no competing interests associated with this publication.

Funding Sources: This research did not receive any specific grant from funding agencies in the public, commercial, or not-for-profit sector.

\section{References:}

1. Ahmad AS, Ormiston-Smith N, Sasieni PD. Trends in the lifetime risk of developing cancer in Great Britain: comparison of risk for those born from 1930 to 1960. Br J Cancer. 2015 Mar 3;112(5):943-7.

2. DeNunzio NJ, Joseph L, Handal R, Agarwal A, Ahuja D, Hirsch AE. Devising the optimal preclinical oncology curriculum for undergraduate medical students in the United States. J Cancer Educ. 2013 Jun;28(2):228-36.

3. Al Suwayri SM. Feasibility and Outcomes of Oncology Teaching for 5th Year Medical Students. J Cancer Educ. 2018 Feb;33(1):83-88.

4. Cave J, Woolf K, Dacre J, Potts HW, Jones A. Medical student teaching in the UK: how well are newly qualified doctors prepared for their role caring for patients with cancer in hospital? $\mathrm{Br} \mathrm{J}$ Cancer. 2007 Aug 20;97(4):472-8.

5. Barton MB, Tattersall MH, Butow PN, Crossing S, Jamrozik K, Jalaludin B, Atkinson $\mathrm{CH}$, Miles SE. Cancer knowledge and skills of interns in Australia and New Zealand in 2001: comparison with 1990, and between course types. Med J Aust. 2003 Mar 17;178(6):285-9.

6. Mayes J, Davies S, Harris A, Wray E, Dark GG. Impact of a 2-Week Oncology Placement on Medical Students' Perception of Cancer. J Cancer Educ. 2018 Feb;33(1):174-179.

7. Bray F, Jemal A, Grey N, Ferlay J, Forman D. Global cancer transitions according to the Human Development Index (2008-2030): a population-based study. Lancet Oncol. 2012 Aug;13(8):790-801.

8. Granek L, Lazarev I, Birenstock-Cohen S, Geffen DB, Riesenberg K, Ariad S. Early exposure to a clinical oncology course during the preclinical second year of medical school. Acad Med. 2015 Apr;90(4):454-7.

9. Smith AP, Lichtveld MY. A competency-based approach to expanding the cancer care workforce. Medsurg Nurs. 2007 Apr;16(2):109-17; quiz 118.

10. Pimentel FL, Ferreira JS, Vila Real M, Mesquita NF, Maia-Gonçalves JP. Quantity and quality of information desired by Portuguese cancer patients. Support Care Cancer. 1999 Nov;7(6):407-12.

11. Fitts WT Jr, Ravdin IS. What Philadelphia physicians tell patients with cancer. J Am Med Assoc. 1953;153:901-4.

12. Thomsen OO, Wulff HR, Martin A, Singer PA. What do gastroenterologists in Europe tell cancer patients? Lancet. 1993 Feb 20;341(8843):473-6.

13. Elger BS, Harding TW. Should cancer patients be informed about their diagnosis and prognosis? Future doctors and lawyers differ. J Med Ethics. 2002 Aug;28(4):258-65. 